\title{
The Role of Spatial Ability in Learning with Virtual Reality: A Literature Review
}

\author{
Yongqian Lin \\ City University of Hong Kong \\ Yongqian.Lin@my.cityu.edu.hk
}

\author{
Ayoung Suh \\ Sungkyunkwan University \\ aysuh@skku.edu
}

\begin{abstract}
No research has systematically reviewed the role of spatial ability in virtual reality (VR) learning. This has resulted in inefficiencies in educators' ability to adopt personalized teaching strategies based on learners, spatial ability to maximize the effectiveness of VR. Therefore, this study conducted a literature review on spatial ability in VR learning to provide researchers and educators with a comprehensive understanding of how spatial ability affects VR learning. After searching Scopus with keywords and applying inclusion and exclusion criteria, the researchers identified 30 relevant research articles for the review. This literature review mainly analyzed research trends, contexts, theories, methodologies, and findings from the identified articles. The contradictory role of spatial ability in VR learning was also summarized. Based on the literature analysis, this study identified research gaps and indicated directions for future research.
\end{abstract}

\section{Introduction}

Virtual reality (VR) has been widely applied in education. Researchers report that the educational application of VR has a positive effect on learning performance [1-3], but these positive effects do not benefit everyone equally [3-5]. The benefits of VR for learning performance are mediated by individual differences. One factor that significantly affects students' learning performance in VR is spatial ability [6-8]. As an individual trait, spatial ability is crucial for influencing learning because it helps learners manipulate visual information and construct mental representations [9]. However, the way by which spatial ability plays a role in VR learning remains unclear. Therefore, this study aims to comprehensively review the empirical research concerning the impact of spatial ability on VR learning, and reveal how spatial ability affects learners' performance when using VR for learning.

This paper describes the concept and underpinning knowledge of VR and spatial ability, followed by a summary of the current state of research on how spatial ability affects VR learning. Second, specific research questions and search procedures for literature are proposed. Then, the results of the 30 identified research articles are summarized and discussed. Finally, implications and future research directions are presented.

\section{Background}

\subsection{VR and learning}

VR is a technology that produces a threedimensional (3-D) virtual environment, allowing users to interact with virtual objects through sensorial devices [10]. There are two categories of VR: non-immersive and immersive. Non-immersive VR is displayed on a computer screen and can be explored with a keyboard, mouse, joystick, and other tools [3,11]. Immersive VR enables users to fully immerse themselves in a virtual environment through stereoscopic displays, such as head-mounted displays (HMDs) and cave automatic virtual environments (CAVEs) [2, 12]. Both VR technologies offer advantages that other technologies do not have, such as 3-D visualization and interactivity. Therefore, VR is widely adopted in various industries, including education.

VR has been widely applied for teaching various disciplines, including astronomy [13], architecture [14], engineering [15], and mathematics [16]. The positive impact of VR on learning performance has also been confirmed [1-3]. However, researchers argue that such positive impact can be easily influenced by learners' individual traits [5]. Therefore, the role of personal traits and their effects on the use of VR in learning should be investigated to maximize the positive impact of VR on learning. The following section introduces one of the critical traits: spatial ability. 


\subsection{Spatial ability}

Researchers have proposed various definitions of spatial ability. For example, Lohman [17] defines spatial ability as "the ability to generate, retain, retrieve, and transform well-structured visual images" (p. 126). According to Linn and Petersen [18], spatial ability refers to "skill in representing, transforming, generating, and recalling symbolic, nonlinguistic information" ( $\mathrm{p}$. 1482). Spatial ability is also considered to be the ability to understand the 3-D structure and position of objects when they are manipulated [19]. Although researchers have proposed different definitions, they agree that spatial ability is a natural ability that helps an individual solve visual and spatial problems.

Spatial ability is not a unitary construct but a collection of subfactors, given that solving spatial problems requires multiple capabilities [20]. Researchers have proposed different subfactors of spatial ability, but there is no consensus. For example, McGee [21] proposed two main subfactors: spatial visualization and spatial orientation. Lohman [22] proposed three main subfactors of spatial ability: spatial visualization, spatial orientation, and speeded rotation. Furthermore, Carroll [23] proposed five factors: visualization, spatial relations, closure speed, flexibility of closure, and perceptual speed. Among all the identified subfactors, the most frequently cited ones are spatial visualization, spatial orientation, and spatial relations [24]. Table 1 lists the definitions of these factors.

Table 1. Definitions of spatial ability subfactors

\begin{tabular}{|l|l|l|}
\hline Subfactor & Definition & Reference \\
\hline $\begin{array}{l}\text { Spatial } \\
\text { visualization }\end{array}$ & $\begin{array}{l}\text { An ability that mentally } \\
\text { manipulates the spatial } \\
\text { structures, imagines how the } \\
\text { objects are rotated, imagines } \\
\text { how the flat patterns are } \\
\text { folded, and imagines how the } \\
\text { objects' position is changed. }\end{array}$ & \\
\hline Spatial & $\begin{array}{l}\text { An ability that understands } \\
\text { the objects consistence in a }\end{array}$ & \\
orientation & $\begin{array}{l}\text { visual stimulus pattern, and } \\
\text { keeps unconfused by the } \\
\text { changeful orientation of the } \\
\text { spatial structures. }\end{array}$ & [25] \\
\hline Spatial & $\begin{array}{l}\text { An ability that makes a } \\
\text { comparison between two } \\
\text { stimuli to distinguish whether } \\
\text { one stations } \\
\text { rotary or a flipped version of } \\
\text { the other. }\end{array}$ & \\
\hline
\end{tabular}

\subsection{Role of spatial ability in learning with VR}

Extensive empirical evidence has identified a significantly positive correlation between spatial ability and learning performance in science, technology, engineering, and mathematics (STEM) subjects [26-28]. This is attributed to the fact that learners need to mentally establish and manipulate visuospatial information using their spatial ability to understand the knowledge in STEM subjects. Therefore, learners with high spatial ability tend to exhibit better learning performance, especially when they learn through traditional methods (e.g., face-to-face lectures) [29]. However, in VR learning, this positive relationship between spatial ability and learning performance is debated. While some studies have validated the significantly positive effects of spatial ability on learning performance $[30,31]$, others have failed to verify these effects $[32,33]$. The insignificant effects are unexpected; however, they can be explained by the ability-as-compensator hypothesis [6, 34].

According to the ability-as-compensator hypothesis, learners with low spatial ability benefit the most from external learning tools because these tools compensate for their lack of spatial ability [34]. In VR learning, low-spatial-ability learners benefit more from the advantages of VR than do high-spatial-ability learners, because the external and explicit representations provided by VR help low-spatial-ability learners efficiently build a mental model of the learning content [34]. Under the compensator hypothesis, highspatial-ability learners do not gain special benefits from VR because they can mentally build visual representations based on static images.

However, the ability-as-compensator hypothesis is not always verified. Some studies support the opposite: the ability-as-enhancer hypothesis [30, 35, 36]. According to the enhancer hypothesis, high-spatialability learners gain more benefits from VR learning because they have high cognitive ability and sufficient cognitive resources to build a mental model of the learning content in a complex virtual environment [26]. Low-spatial-ability learners benefit less from VR learning because they need higher cognitive resources to manage the interaction or visual detail processing in the VR learning environment [37].

These two contradictory hypotheses raise the question of whether VR is more beneficial for low- or high-spatial-ability learners. Moreover, the impact of VR on learners with different spatial abilities may be affected by the technical features of VR, such as dimensionality [28], interactivity [38], and visualization [34]. However, how these VR features exert their influence is inconclusive. 


\section{Research questions and methodologies}

\subsection{Research questions}

Despite the continuous research interest in spatial ability, there is no comprehensive understanding of the trends, methodologies, and findings of research concerning spatial ability in VR learning. Moreover, the relationship between spatial ability and learning performance in VR and how this relationship is affected by VR features is uncertain. On the basis of this research background, this study aims to conduct a literature review and answer the following question: What are the research trends, contexts, foci, theoretical foundations, methods, and findings of VR learning research about spatial ability? By answering this question, this study reveals the current state of research about the role of spatial ability in VR learning.

\subsection{Methodologies}

To identify articles about the influence of spatial ability on VR learning, we first searched the key data source, Scopus, from 2001 to the present. Focusing on one database can ensure the reproducibility, rigor, and transparency of the search [39]. To ensure the quality of the searched papers, we targeted peer-reviewed journal articles indexed in the Social Sciences Citation Index (SSCI) or Science Citation Index (SCI). Furthermore, some peer-reviewed conference papers were included considering the fact that a large amount of innovative research about immersive VR was published in conferences instead of journals. Extensive keywords representing "spatial ability", "learning", and "virtual reality" were used to search for relevant articles. With these keywords, we found 2023 relevant articles. Second, we limited the search to journal and conference articles in the social sciences area to refine the results. After this stage, 534 relevant articles were left. Then, we applied the inclusion and exclusion criteria to filter the searched articles and identify appropriate articles. To be included in this review, the articles should meet all of the following conditions: (1) studying the use of VR, (2) addressing issues associated with learners' spatial ability, and (3) focusing on academic learning. The exclusion criteria allowed us to exclude articles with no empirical data and articles that did not examine the relationship between spatial ability and learning performance. These exclusion criteria were applied because this review aims to summarize research findings regarding the influence of spatial ability on VR learning performance, which is demonstrated by empirical results. Based on the application of these criteria, we identified 25 relevant research articles.
Subsequently, we performed backward and forward searches of these 25 articles and found 5 other relevant research articles. Ultimately, 30 related research articles were identified for the literature analysis. Figure 1 demonstrates the process of searching and selecting the studies. After we identified the articles used for literature analysis, we coded them and collected the following data: (1) bibliometric information (including authors and publication years), (2) research methods, and (3) research contexts. The analysis of the identified articles is presented in the next section.

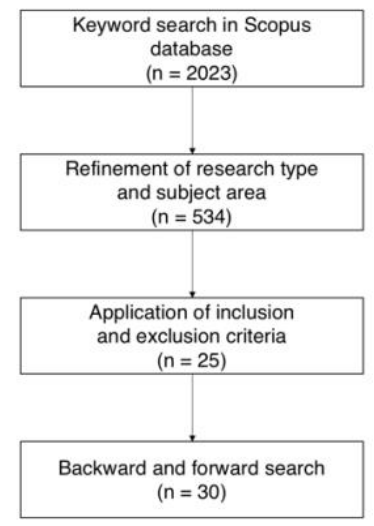
Figure 1. The process of searching and
selecting literature

\section{Results}

\subsection{Research trends and background}

We first collected the bibliometric data of the selected literature. Figure 2 shows the number of publications since 2001. In general, spatial ability has attracted research attention over the years. Since 2006, researchers' interest in spatial ability has increased significantly, which is proved by the rapid growth of the publications number after 2006 . We attribute the rapid growth to the advancement of technology and the popularity of VR in education. The number of publications has declined slightly after 2016 because 2020 is not over yet, resulting in only part of articles in 2020 being included.

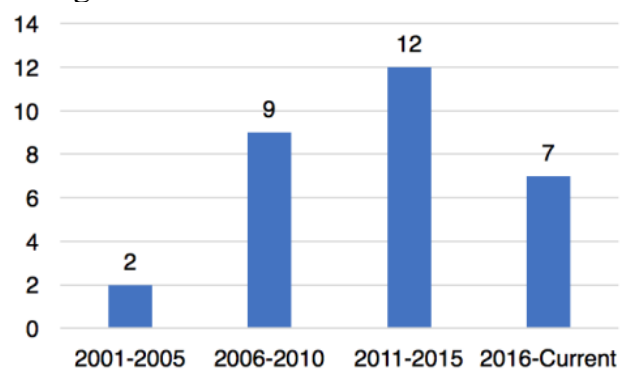

Figure 2. The number of publications 
Figure 3 shows the learning contexts of selected literature. Most of the research contexts are related to STEM learning, which can be attributed to the importance of spatial ability in learning STEM subjects. $63 \%(\mathrm{n}=19)$ of the selected studies focused on learning anatomy, followed by chemistry $(13 \%, \mathrm{n}=4)$. A large proportion of the research focused on anatomy learning because of the high requirements for spatial ability and the widespread adoption of VR in anatomy learning [40].

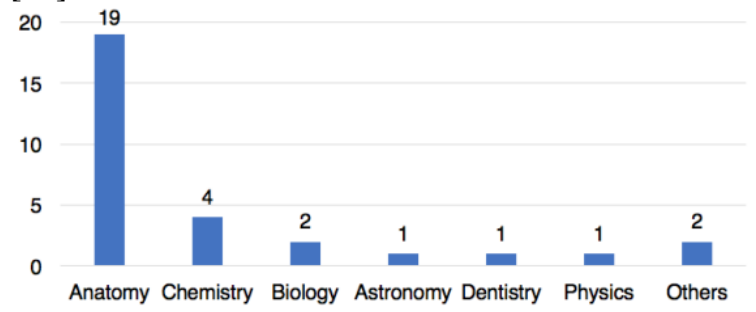

Figure 3. Learning contexts

$90 \%(\mathrm{n}=27)$ of the research studied non-immersive $\mathrm{VR}$, and only $10 \%(\mathrm{n}=3)$ of the research studied immersive VR. The larger amount of research concerning non-immersive VR is attributed to better development, lower price, easier usage, and wider application of it. In comparison, immersive VR has not been popularized in education because it is more difficult to use and more expensive, resulting in less research focusing on it.

\subsection{Theoretical foundations}

Table 2 summarizes the adopted theoretical foundations (i.e., cognitive load theory, aptitudetreatment interactions, and working memory model) in the selected articles. Unexpectedly, out of 30 articles, only 4 articles discussed the theoretical foundations of spatial ability effects. Most of the identified articles were experimental and focused on examining the effects of spatial ability without discussing supporting theories.

Table 2. Theoretical foundations

\begin{tabular}{|l|l|l|}
\hline Theory & Description & Reference \\
\hline & $\begin{array}{l}\text { It explains the boundedness of } \\
\text { working memory from the } \\
\text { perspective of human }\end{array}$ & \\
Cognitive & $\begin{array}{l}\text { cognitive architecture. } \\
\text { According to this theory, the } \\
\text { load theory of spatial ability on }\end{array}$ & {$[3,6,28]$} \\
& $\begin{array}{l}\text { learning performance are } \\
\text { regulated by the cognitive load } \\
\text { that learners experience. }\end{array}$ & \\
\hline $\begin{array}{l}\text { Aptitude- } \\
\text { treatment } \\
\text { interactions }\end{array}$ & $\begin{array}{l}\text { It explains that instructional } \\
\text { strategies' effectiveness will } \\
\text { be improved if the strategies }\end{array}$ & {$[3,28]$} \\
\hline
\end{tabular}

\begin{tabular}{|c|c|c|}
\hline & $\begin{array}{l}\text { are adapted to learners' } \\
\text { abilities or attributes. } \\
\text { According to this theory, it is } \\
\text { more effective to adopt } \\
\text { different teaching strategies } \\
\text { based on learners' different } \\
\text { spatial abilities. }\end{array}$ & \\
\hline $\begin{array}{l}\text { Working } \\
\text { memory } \\
\text { model }\end{array}$ & $\begin{array}{l}\text { It explains that the visual and } \\
\text { spatial information is } \\
\text { processed in the visuospatial } \\
\text { scratchpad, a specific part of } \\
\text { the working memory. The } \\
\text { limited processing capacity in } \\
\text { this memory system affects } \\
\text { individuals' understanding of } \\
\text { spatial information. } \\
\text { According to this theory, high- } \\
\text { spatial-ability learners have } \\
\text { higher processing capacity in } \\
\text { the visuospatial scratchpad; } \\
\text { therefore, the manipulation of } \\
\text { visuospatial information is } \\
\text { easier for them, and they can } \\
\text { gain better learning } \\
\text { performance. }\end{array}$ & [41] \\
\hline
\end{tabular}

\subsection{Research methods}

As shown in Figure 4, various methods have been adopted to investigate the impact of spatial ability on VR learning, including experiment, survey, and interview. There are $43 \%(\mathrm{n}=13)$ of the studies combining multiple research methods. Among these methods, the most popular one is the experiment, followed by the survey. The experimental method was adopted to examine the relationship between spatial ability and learning performance. The survey method was adopted to measure unobservable constructs (e.g., cognitive load and usability), or learners' psychological factors (e.g., motivation and enjoyment).

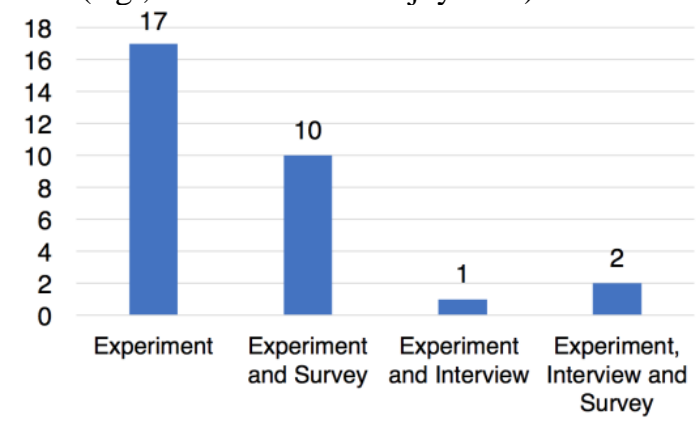

Figure 4. Research methods

\subsection{Research findings}

The literature analysis demonstrates three main streams in the research findings of spatial ability in VR 
learning. The first stream mainly focuses on the direct impact of spatial ability on learning performance. For example, Kurul et al. [33] studied whether learners' spatial ability affects their learning performance in VR. The second stream is to compare VR with other learning tools (e.g., textbooks and PowerPoint slides), and investigate whether VR compensates low-spatial-ability learners or enhances high-spatial-ability learners. For example, Sun, $\mathrm{Wu}$, and Cai [6] investigated two learning interventions (i.e., PowerPoint slides and VR) to compare the influence of these interventions on learning performance and to examine how spatial ability affects the influence. The third stream plays an emphasis on VR features that bring different benefits to learners with low and high spatial ability. For example, Jang et al. [8] studied the manipulation function of VR and concluded that low-spatial-ability learners tended to have more advantages than high-spatial-ability learners when they were allowed to freely manipulate the virtual objects. Following these three streams, the main research findings are elaborated in the following parts.

\subsubsection{Direct impact of spatial ability on learning} performance. In VR learning, there are contradictory research results about the impact of spatial ability on learning performance. As shown in Figure 5, 53\% (n = 16) of the research verified the positive correlation between spatial ability and learning performance, which means high-spatial-ability learners tend to achieve better academic performance. However, $17 \%(n=5)$ of the research failed to confirm the positive relationship. Moreover, 20\% $(n=6)$ of the studies indicated that whether the positive relationship is significant, is affected by many factors (e.g., VR features, knowledge dimensions, and learning tasks). The influencing factors and the corresponding results are listed in Table 3 . The remaining $10 \%(\mathrm{n}=3)$ of the research did not examine the direct relationship between spatial ability and learning performance.

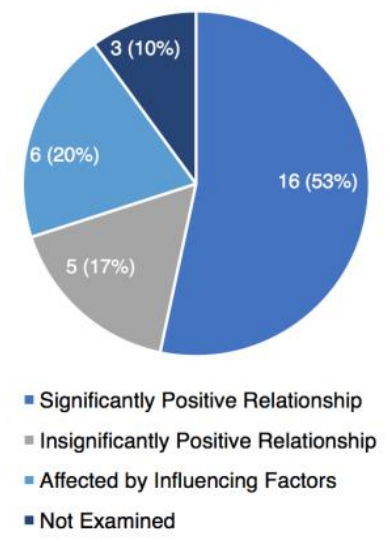
Figure 5. Results of the relationship between
spatial ability and learning performance
4.4.2. The ability-as-compensator and the ability-asenhancer hypotheses. Because many studies have proven the gap between low- and high-spatial-ability learners' performance, researchers are concerned about whether this gap will be narrowed or widened with the intervention of VR. The ability-as-compensator and the ability-as-enhancer hypotheses help to answer this question. According to the ability-as-compensator hypothesis, the use of VR will shrink the learning performance gap because VR brings more benefits to low-spatial-ability learners. However, the ability-asenhancer hypothesis proposes that learners with high spatial ability benefit more from VR, thus widening the performance gap between learners with high and low spatial ability.

To test the above hypotheses, 6 out of 30 identified research studied the interaction effects of spatial ability and VR on learning performance. Among them, 1 research supported the ability-as-enhancer hypothesis. In this study, the authors examined the interaction effects of learning interventions (i.e., mobile application and non-immersive VR) and spatial ability on learning performance [36]. The results showed that high-spatialability learners benefited more than low-spatial-ability learners from VR learning.

4 research confirmed the ability-as-compensator hypothesis. For example, Lee and Wong [3] compared the performance of learners in the experimental group (learning with VR) and the control group (learning with PowerPoint slides). They found that low-spatial-ability learners in the experimental group performed significantly better than those in the control group. However, there was no statistically significant difference in performance between the two groups of high-spatial-ability learners. Some researchers believe that the ability-as-compensator hypothesis is supported because low-spatial-ability learners perceive lower cognitive load when learning with VR than with other learning interventions [6, 9]. Other learning interventions (e.g., instruction with PowerPoint slides) separate language information and corresponding visual information; therefore, learners need to match all information by themselves to build mental models. This process requires repeated processing of language and image information, consuming learners' cognitive resources, especially for low-spatial-ability learners [6]. Moreover, when learning spatial knowledge with traditional learning interventions (e.g., textbooks and PowerPoint slides), learners need to mentally convert two-dimensional (2-D) objects into 3-D objects, which is difficult for low-spatial-ability learners and results in their higher cognitive load. In contrast, VR provides learners with dynamic and continuous image presentations, 3-D visualization, and multiple sensory channels. These functions help low-spatial-ability 
Table. 3 Factors that affect the relationship between spatial ability and learning performance

\begin{tabular}{|c|c|c|c|}
\hline $\begin{array}{l}\text { Influencing } \\
\text { Factor }\end{array}$ & Description & Conclusion & Reference \\
\hline $\begin{array}{l}\text { Manipulation } \\
\text { (Manipulation } \\
\text { VS Viewing) }\end{array}$ & $\begin{array}{l}\text { Manipulation: Participants actively manipulated the } \\
\text { virtual structures by controlling the "trigger" button } \\
\text { and the joystick. } \\
\text { Viewing: Participants learnt from watching the } \\
\text { video, which showed the movement and } \\
\text { transformation of the 3-D models. }\end{array}$ & $\begin{array}{l}\text { The results revealed a positive correlation } \\
\text { between spatial ability and learning } \\
\text { performance for the viewing condition, but } \\
\text { there was no correlation for the } \\
\text { manipulation condition. }\end{array}$ & [8] \\
\hline $\begin{array}{l}\text { Stereopsis } \\
\text { (Stereoptic } \\
\text { VS Binocular) } \\
\text { And } \\
\text { Interactivity }\end{array}$ & $\begin{array}{l}\text { Stereoptic and extensive interactivity: Participants } \\
\text { acquired knowledge in VR that involved } \\
\text { stereoscopic vision and extensive interaction. } \\
\text { Biocular and limited interactivity: Participants } \\
\text { acquired knowledge in VR that involved biocular } \\
\text { information presentation and limited interaction. }\end{array}$ & $\begin{array}{l}\text { The results revealed a positive correlation } \\
\text { between spatial ability and learning } \\
\text { performance for the biocular condition, but } \\
\text { there was no correlation for the stereoptic } \\
\text { condition. }\end{array}$ & {$[38]$} \\
\hline $\begin{array}{l}\text { Assessment } \\
\text { difference } \\
\text { (Outside } \\
\text { shape VS } \\
\text { Duct location) }\end{array}$ & $\begin{array}{l}\text { Outside shape: Participants were scored based on } \\
\text { the outer shape of an anatomy-like structure that } \\
\text { they drew. } \\
\text { Duct location: Participants were scored based on } \\
\text { ducts position and spatial relations among ducts of } \\
\text { an anatomy-like structure that they drew. }\end{array}$ & $\begin{array}{l}\text { The results revealed a positive correlation } \\
\text { between spatial ability and learning } \\
\text { performance for the duct location measure, } \\
\text { but there was no correlation for the outside } \\
\text { shape measure. }\end{array}$ & \multirow{2}{*}[42]{} \\
\hline $\begin{array}{l}\text { Control } \\
\text { (Active } \\
\text { control VS } \\
\text { Passive } \\
\text { viewing) }\end{array}$ & $\begin{array}{l}\text { Active control: Participants could freely rotate and } \\
\text { control computer visualization. } \\
\text { Passive viewing: Participants could not control the } \\
\text { movements of virtual objects. }\end{array}$ & $\begin{array}{l}\text { The results revealed a marginally positive } \\
\text { correlation between spatial ability and } \\
\text { learning performance for the duct location } \\
\text { measure under passive viewing, but there } \\
\text { was no correlation for the duct location } \\
\text { measure under active viewing. }\end{array}$ & \\
\hline $\begin{array}{l}\text { Knowledge } \\
\text { dimension } \\
\text { (Factual } \\
\text { knowledge } \\
\text { VS } \\
\text { Conceptual } \\
\text { knowledge) }\end{array}$ & $\begin{array}{l}\text { Factual knowledge: Participants were tested for } \\
\text { factual knowledge, the knowledge of terminology, } \\
\text { including technical vocabulary, facts, and essential } \\
\text { elements. } \\
\text { Conceptual knowledge: Participants were tested for } \\
\text { conceptual knowledge that allowed them to } \\
\text { classify, categorize, and generalize the learning } \\
\text { about theories, models, and structures. }\end{array}$ & $\begin{array}{l}\text { The results revealed a positive correlation } \\
\text { between spatial ability and conceptual } \\
\text { knowledge acquisition, but there was no } \\
\text { correlation for the factual knowledge } \\
\text { acquisition. }\end{array}$ & {$[41]$} \\
\hline $\begin{array}{l}\text { Task } \\
\text { difference }\end{array}$ & $\begin{array}{l}\text { Participants were required to take different tasks, } \\
\text { including feature identification task, movement } \\
\text { identification task, movement order task, scapula } \\
\text { relative rotations task, and orientation reference } \\
\text { task. }\end{array}$ & $\begin{array}{l}\text { The results revealed a positive correlation } \\
\text { between spatial ability and performance of } \\
\text { feature identification task, movement } \\
\text { identification task, and movement order } \\
\text { task. They also revealed a marginally } \\
\text { positive correlation between spatial ability } \\
\text { and performance of scapula relative } \\
\text { rotations task; but there was no correlation } \\
\text { in the orientation references task. }\end{array}$ & {$[34]$} \\
\hline
\end{tabular}

learners easily convert spatial information and reduce their cognitive load so that these learners are able to apply more working memory to process learning content and eventually gain better learning performance [3]. For high-spatial-ability learners, because they are good at managing spatial information, they are able to complete spatial learning tasks with few cognitive resources regardless of the learning intervention. Therefore, VR is not necessary and advantageous for them [6, 43].

Moreover, there is 1 research concluding that the interaction effects of learning intervention and spatial ability are not significant [44].

In general, although both the compensator and enhancer hypotheses have been verified, more studies supported the compensator hypothesis. After analysis, we concluded that the compensator hypothesis is usually supported when researchers compare VR with traditional and non-interactive learning interventions. However, when VR is compared with other interactive learning interventions (e.g., mobile application), the compensator hypothesis may be objected.

4.4.3. Influence of VR features. Although many studies have supported the ability-as-compensator hypothesis, it does not mean that all VR features bring more benefits to learners with low spatial ability. In fact, some VR features compensate low-spatial-ability learners, while some VR features enhance the 
Table. 4 Various impact of VR features on different-spatial-ability learners

\begin{tabular}{|c|c|c|c|}
\hline VR feature & Description & Conclusion & Reference \\
\hline $\begin{array}{l}\text { Manipulation } \\
\text { (Manipulation VS } \\
\text { Viewing) }\end{array}$ & $\begin{array}{l}\text { Manipulation: Participants actively manipulated the virtual } \\
\text { structures by controlling the "trigger" button and the joystick. } \\
\text { Viewing: Participants learnt from watching the video, which } \\
\text { showed the movement and transformation of the } 3 \text {-D models. }\end{array}$ & $\begin{array}{l}\text { Low-spatial-ability } \\
\text { learners benefited more } \\
\text { from manipulation than } \\
\text { high-spatial-ability } \\
\text { learners. }\end{array}$ & {$[8]$} \\
\hline $\begin{array}{l}\text { Device location } \\
\text { (Co-located location } \\
\text { VS Displaced } \\
\text { location) }\end{array}$ & $\begin{array}{l}\text { Co-located location: The direct manipulation device and } \\
\text { virtual images were co-located. } \\
\text { Displaced location: The manipulation device was in a } \\
\text { different spatial location from the virtual images. }\end{array}$ & $\begin{array}{l}\text { Low-spatial-ability } \\
\text { learners benefited more } \\
\text { from co-location than } \\
\text { high-spatial-ability } \\
\text { learners. }\end{array}$ & \multirow{2}{*}{ [28] } \\
\hline $\begin{array}{l}\text { Viewing } \\
\text { (Stereoscopic } \\
\text { viewing VS } \\
\text { Monoscopic } \\
\text { viewing) }\end{array}$ & $\begin{array}{l}\text { Stereo viewing provided learners with an extra depth cue of } \\
\text { binocular disparity, as compared with monoscopic viewing. }\end{array}$ & $\begin{array}{l}\text { Low-spatial-ability } \\
\text { learners benefited more } \\
\text { from stereo viewing than } \\
\text { high-spatial-ability } \\
\text { learners. }\end{array}$ & \\
\hline $\begin{array}{l}\text { Exploration (Active } \\
\text { exploration VS } \\
\text { Passive exploration) }\end{array}$ & $\begin{array}{l}\text { Active exploration: Participants were allowed to interactively } \\
\text { explore and freely rotate the virtual objects through a computer } \\
\text { mouse. } \\
\text { Passive exploration: Participants were allowed to watch the } \\
\text { recording and observe the } 3 \text {-D virtual objects, but the } \\
\text { interaction was impossible. }\end{array}$ & $\begin{array}{l}\text { Low-spatial-ability } \\
\text { learners benefited more } \\
\text { from active exploration } \\
\text { than middle- and high- } \\
\text { spatial-ability learners. }\end{array}$ & {$[45]$} \\
\hline $\begin{array}{l}\text { Interactivity } \\
\text { (Limited } \\
\text { interactivity } \\
\text { Extended } \\
\text { interactivity) }\end{array}$ & $\begin{array}{l}\text { Limited interactivity: Participants were allowed to click to } \\
\text { switch the displayed images. } \\
\text { Extended interactivity: Participants were allowed to actively } \\
\text { rotate and view the virtual 3-D objects in any directions with } \\
\text { the mouse. }\end{array}$ & \multirow{2}{*}{$\begin{array}{l}\text { Low-spatial-ability } \\
\text { learners benefited more } \\
\text { from the combination of } \\
\text { interactivity and } \\
\text { stereopsis than high- } \\
\text { spatial-ability learners. }\end{array}$} & \multirow{2}{*}[38]{} \\
\hline $\begin{array}{lr}\text { Visual } & \text { Feedback } \\
\text { (Biocular } & \text { feedback } \\
\text { VS } & \text { Stereoptic } \\
\text { feedback) } & \end{array}$ & $\begin{array}{l}\text { Biocular feedback: Participants were allowed to learn from 2- } \\
\text { D visual information. } \\
\text { Stereoptic feedback: Participants were allowed to wear } \\
\text { shutter-glasses to perceive depth and learn from computerized } \\
\text { 3-D constructions. }\end{array}$ & & \\
\hline $\begin{array}{l}\text { Visualization } \\
\text { (Dynamic } \\
\text { visualization VS } \\
\text { Static visualization) }\end{array}$ & $\begin{array}{l}\text { Dynamic visualization: Participants were provided with direct } \\
\text { visualization that showed the changing process throughout the } \\
\text { viewpoints. } \\
\text { Static visualization: Participants were required to mentally } \\
\text { imagine and manipulate } 3 \text {-D relationships of virtual objects } \\
\text { from the demonstrated 2-D representations. }\end{array}$ & $\begin{array}{l}\text { Low-spatial-ability } \\
\text { learners benefited more } \\
\text { from dynamic } \\
\text { visualization than high- } \\
\text { spatial-ability learners. }\end{array}$ & {$[34]$} \\
\hline $\begin{array}{l}\text { Control } \\
\text { (Active control VS } \\
\text { Passive control) }\end{array}$ & $\begin{array}{l}\text { Active control: Participants were allowed to freely interact } \\
\text { with the 3-D virtual objects in VR. } \\
\text { Passive control: Participants were allowed to observe 3-D } \\
\text { scenes' key view through clicking the buttons, but the rotation } \\
\text { and zooming of the 3-D scenes were not allowed. }\end{array}$ & $\begin{array}{l}\text { High-spatial-ability } \\
\text { learners benefited more } \\
\text { from active control than } \\
\text { low-spatial-ability } \\
\text { learners. }\end{array}$ & {$[35]$} \\
\hline
\end{tabular}

performance of high-spatial-ability learners. In the reviewed articles, 6 of them examined the VR features that have various impact on learners with different spatial abilities. Table 4 lists the descriptions of these VR features and the conclusion.

5 articles introduced the VR features that supported the compensator hypothesis, including manipulation [8], active exploration [45], co-location of devices and images [28], stereo viewing [28], the combination of stereopsis and interactivity [38], and dynamic visualization [34]. The remaining 1 article supported the enhancer hypothesis and concluded that active control benefits high-spatial-ability learners more [35].
It should be noted that manipulation [8], active exploration [45], interactivity [38], and active control [35] are similar in definition and can be categorized as interactivity. It is because these four features all describe the functions of VR that allow learners to actively rotate and interact with the virtual objects by controlling a mouse, button, or joystick. In the four studies focusing on interactivity, three of them concluded that learners with low spatial ability benefit more than those with high spatial ability when they are allowed to freely interact with the virtual objects in $\operatorname{VR}[8,38,45]$. Another study proved that low-spatial-ability learners' learning was hindered when they were allowed to freely control the virtual environment [35]. Researchers have 
provided explanations for these contradictory findings. To explain the compensatory effects of interactivity, Luursema et al. [38] proposed that interactivity allows learners to use their bodies as reference systems to maintain orientation in a virtual environment. Without interactivity, learners need to rely on their spatial ability to maintain the orientation. Therefore, interactivity reduces the difficulty of learning tasks, especially for low-spatial-ability learners. Another possible explanation is that interactivity allows learners to explore virtual 3-D objects in real-time, effectively reducing the cognitive burden of learners with low spatial ability, thereby improving their learning performance. In contrast, Qi et al. [35] also proposed the explanation for their finding that interactivity benefits high-spatial-ability learners more. They addressed that too much control of VR may distract learners' attention and increase their extraneous cognitive load, making it easier for low-spatial-ability learners to exceed their total cognitive capacity.

Overall, these research findings help to explain why high- and low-spatial-ability learners gain different benefits from VR learning and provide some references for improving educational VR applications.

\section{Discussion}

Spatial ability and its impact on learning have always been concerned; however, few studies have systematically analyzed the role of spatial ability in VR learning. Therefore, this study reviewed previous literature that focused on spatial ability in VR learning and discussed how learners' performance is affected by their spatial ability. Based on the literature analysis, we discuss the implications and future research directions in the following sections.

\subsection{Implications}

This literature review generates both theoretical and practical implications, which contribute to academia and the VR industry. From the theoretical perspective, this review first helps researchers fully understand the research status of spatial ability in VR learning through summarizing bibliometric information, research methods, and findings of relevant articles. Second, this review comprehensively summarized and analyzed the research findings and rationale of the important contradictory arguments, ability-as-enhancer and ability-as-compensator hypotheses in the VR learning context. It provides theoretical references for future research regarding the impact of various VR technologies on learners with different spatial abilities.

From the practical perspective, this review provides new insights for educators and VR application designers who expect to improve learners' performance with VR. This review reminds educators that VR does not play the same role for all learners so that they should adopt personalized teaching strategies and apply VR according to learners' spatial ability. To be specific, educators are advised to adopt both VR and other teaching technologies to provide different-spatialability learners with various and appropriate instructions. Moreover, this study summarized the VR features that affect the performance of different-spatial-ability learners, providing VR application designers with references to improve their educational VR applications. In general, this review will benefit both researchers and practitioners who are interested in VR learning.

\subsection{Future research directions}

5.2.1. Examining the ability-as-enhancer and abilityas-compensator hypotheses in the immersive VR context. The literature analysis shows that most of the spatial ability research focused on non-immersive VR $[3,7,32]$, and little research studied immersive VR [6]. The lack of spatial ability research in immersive VR context generates a research gap that it is unknown whether the ability-as-enhancer or ability-ascompensator hypotheses will be supported in immersive VR learning. In recent years, this research gap has become important because the adoption of immersive VR in education has increased, and educators need to understand how immersive VR influences differentspatial-ability learners to appropriately adopt immersive VR. Therefore, researchers are advised to verify the two contradictory hypotheses by comparing the influence of immersive VR and other technologies on learners with different spatial abilities.

5.2.2. Developing more applicable theories. The literature analysis shows that only three theories (i.e., cognitive load theory, aptitude-treatment interactions, and working memory model) have been proposed to analyze the effects of spatial ability and the rationale of the ability-as-enhancer and ability-as-compensator hypotheses. Moreover, only $13 \%$ of the identified literature has presented relevant theories to support its research and discussion about the role of spatial ability $[3,6,28,41]$. Most of the literature simply put forward research questions based on previous research findings and adopted experimental methods to investigate the role of spatial ability without rigorous theoretical foundations [8, 34-36, 45, 46]. Future research is suggested to adopt or develop more theories to explain the effects of spatial ability on VR learning, as well as the rationale of the enhancer and compensator hypotheses. 
5.2.3. Measuring cognitive load. The literature analysis shows that cognitive load theory is the most commonly used theory to explain the ability-asenhancer and ability-as-compensator hypotheses [3, 6, $28]$. According to the cognitive load theory, learning interventions affect the performance of differentspatial-ability learners by adjusting their cognitive load. For example, Lee and Wong [3] proposed that VR compensates low-spatial-ability learners by reducing their extraneous cognitive load and increasing their germane cognitive load. However, among the selected articles, only one article measured learners' cognitive load [6]. The other articles did not provide any empirical evidence to support their discussion about the cognitive load [3, 28], making their inferences difficult to convince readers. Therefore, if future research aims to explore the effects of spatial ability based on cognitive load theory, it is suggested to include the measurement of cognitive load.

5.2.4. Investigating factors that affect the role of spatial ability. The literature analysis shows that little research studied why the ability-as-compensator or ability-as-enhancer hypotheses will be supported in VR learning. Among the little research, most of them focused on technical VR features (e.g., interactivity, dimensionality, and degree of control), and studied the interaction effects of these features and spatial ability, providing some explanations for those hypotheses $[8,38$, 45]. However, there are many other influencing factors (e.g., learners' psychological factors and learning tasks) that are worth exploring but are not thoroughly studied. Therefore, researchers are advised to study other possible factors that may affect the role of spatial ability in VR learning.

\section{Conclusion}

This systematic literature review presented the research status of spatial ability in VR learning through summarizing the trends, methodologies, and findings of relevant research. The analysis revealed that although there is increasing research interest in the impact of spatial ability on VR learning, few consensus and uniform theories exist in this field to explain how VR influences learners with different spatial abilities. Therefore, this review suggests a need for building more comprehensive theories and examining the factors that affect the interaction effects of spatial ability and VR.

This review has several limitations. First, this review only included empirical studies, resulting in the exclusion of speculative and theoretical articles. However, there might be some important theories discussed in theoretical articles. Further work may review the role of spatial ability and relevant theories in theoretical papers. Second, Scopus was the only database for searching the reviewed articles. Although we believe that Scopus indexes all other possibly related databases, there might be some related articles that are not included in Scopus and were omitted by this review.

\section{References}

[1] L. Freina and M. Ott. A literature review on immersive virtual reality in education: state of the art and perspectives. in The International Scientific Conference eLearning and Software for Education. 2015. "Carol I" National Defence University.

[2] B. Chavez and S. Bayona. Virtual Reality in the Learning Process. in World Conference on Information Systems and Technologies. 2018. Springer.

[3] E.A.L. Lee and K.W. Wong, "Learning with desktop virtual reality: Low spatial ability learners are more positively affected", Computers \& Education, 2014, pp. 49-58.

[4] J. Vindenes, A.O. de Gortari, and B. Wasson. Mnemosyne: adapting the method of loci to immersive virtual reality. in International conference on Augmented Reality, Virtual Reality and Computer Graphics. 2018. Springer.

[5] L. Zhang, D.A. Bowman, and C.N. Jones. Exploring Effects of Interactivity on Learning with Interactive Storytelling in Immersive Virtual Reality. in 2019 11th International Conference on Virtual Worlds and Games for Serious Applications (VS-Games). 2019. IEEE.

[6] R. Sun, Y.J. Wu, and Q. Cai, "The effect of a virtual reality learning environment on learners' spatial ability", Virtual Reality, 2019, pp. 385-398.

[7] Z. Merchant, E.T. Goetz, W. Keeney-Kennicutt, L. Cifuentes, O. Kwok, and T.J. Davis, "Exploring 3-D virtual reality technology for spatial ability and chemistry achievement", Journal of Computer Assisted Learning, 2013, pp. 579-590.

[8] S. Jang, J.M. Vitale, R.W. Jyung, and J.B. Black, "Direct manipulation is better than passive viewing for learning anatomy in a three-dimensional virtual reality environment", Computers \& Education, 2017, pp. 150-165.

[9] T.N. Höffler, "Spatial ability: Its influence on learning with visualizations - a meta-analytic review", Educational psychology review, 2010, pp. 245-269.

[10] C. Dede, "The evolution of constructivist learning environments: Immersion in distributed, virtual worlds", Educational technology, 1995, pp. 46-52.

[11] A. Suh and J. Prophet, "The state of immersive technology research: A literature analysis", Computers in Human Behavior, 2018, pp. 77-90.

[12] F. Biocca and B. Delaney, "Immersive virtual reality technology", Communication in the age of virtual reality, 1995, pp. 32.

[13] C.H. Chen, J.C. Yang, S. Shen, and M.C. Jeng, "A desktop virtual reality earth motion system in astronomy education", Journal of Educational Technology \& Society, 2007, pp. 289-304.

[14] M. Barrett and J. Blackledge, "Evaluation of a prototype desktop virtual reality model developed to enhance electrical safety and design in the built environment”, 2012. 
[15] M.T. Valdez, C.M. Ferreira, and F.M. Barbosa. Electrical engineering teaching and distance learning using a desktop virtual reality system. in 2013 48th International Universities' Power Engineering Conference (UPEC). 2013. IEEE.

[16] H. Kaufmann, D. Schmalstieg, and M. Wagner, "Construct3D: a virtual reality application for mathematics and geometry education", Education and information technologies, 2000, pp. 263-276.

[17] D.F. Lohman, Spatial Ability: A Review and Reanalysis of the Correlational Literature. 1979, Stanford Univ Calif School of Education.

[18] M.C. Linn and A.C. Petersen, "Emergence and characterization of sex differences in spatial ability: A metaanalysis", Child development, 1985, pp. 1479-1498.

[19] A.X. Garg, G. Norman, and L. Sperotable, "How medical students learn spatial anatomy”, The Lancet, 2001, pp. 363 364.

[20] O. Ha and N. Fang, "Spatial ability in learning engineering mechanics: Critical review", Journal of Professional Issues in Engineering Education and Practice, 2016, pp. 04015014.

[21] McGee, M.G., Human spatial abilities: Sources of sex differences, Praeger, 1979.

[22] D.F. Lohman, "Spatial abilities as traits, processes, and knowledge", 1988.

[23] J.B. Carroll, Human cognitive abilities: A survey of factor-analytic studies. Cambridge University Press, 1993.

[24] R. Colom, M.J. Contreras, J. Botella, and J. Santacreu, "Vehicles of spatial ability", Personality and Individual Differences, 2002, pp. 903-912.

[25] M.G. McGee, "Human spatial abilities: Psychometric studies and environmental, genetic, hormonal, and neurological influences", Psychological bulletin, 1979, pp. 889.

[26] T. Huk, "Who benefits from learning with 3D models? The case of spatial ability", Journal of computer assisted learning, 2006, pp. 392-404.

[27] E.D. Ragan, K.J. Huber, B. Laha, and D.A. Bowman. The effects of navigational control and environmental detail on learning in 3D virtual environments. in 2012 IEEE Virtual Reality Workshops (VRW). 2012. IEEE.

[28] T.J. Barrett and M. Hegarty, "Effects of interface and spatial ability on manipulation of virtual models in a STEM domain”, Computers in Human Behavior, 2016, pp. 220-231. [29] N. Seery, J. Buckley, and T. Delahunty. Developing a spatial ability framework to support spatial ability research in engineering education. in Sixth International Research in Engineering Education Symposium. 2015. REES.

[30] A.J. Levinson, B. Weaver, S. Garside, H. McGinn, and G.R. Norman, "Virtual reality and brain anatomy: A randomised trial of e-learning instructional designs", Medical education, 2007, pp. 495-501.

[31] Z. Merchant, E.T. Goetz, W. Keeney-Kennicutt, O.M. Kwok, L. Cifuentes, and T.J. Davis, "The learner characteristics, features of desktop 3D virtual reality environments, and college chemistry instruction: A structural equation modeling analysis", Computers \& Education, 2012, pp. 551-568.

[32] F. Bork, L. Stratmann, S. Enssle, U. Eck, N. Navab, J. Waschke, and D. Kugelmann, "The benefits of an augmented reality magic mirror system for integrated radiology teaching in gross anatomy", Anatomical sciences education, 2019, pp. 585-598.

[33] R. Kurul, M.N. Ögün, A. Neriman Narin, Ş. Avci, and B. Yazgan, "An Alternative Method for Anatomy Training: Immersive Virtual Reality", Anatomical Sciences Education, 2020.

[34] S. Berney, M. Bétrancourt, G. Molinari, and N. Hoyek, "How spatial abilities and dynamic visualizations interplay when learning functional anatomy with 3D anatomical models", Anatomical sciences education, 2015, pp. 452-462. [35] S. Qi, Y. Yan, R. Li, and J. Hu, "The impact of active versus passive use of 3D technology: A study of dental students at Wuhan University, China", Journal of dental education, 2013, pp. 1536-1542.

[36] J.Y. Wang, H.K. Wu, and Y.S. Hsu, "Using mobile applications for learning: Effects of simulation design, visualmotor integration, and spatial ability on high school students' conceptual understanding", Computers in Human Behavior, 2017, pp. 103-113.

[37] R.E. Mayer, Multimedia learning, in Psychology of learning and motivation, Elsevier, 2002, pp. 85-139.

[38] J.M. Luursema, W.B. Verwey, P.A. Kommers, R.H. Geelkerken, and H.J. Vos, "Optimizing conditions for computer-assisted anatomical learning", Interacting with Computers, 2006, pp. 1123-1138.

[39] B. Morschheuser, J. Hamari, J. Koivisto, and A. Maedche, "Gamified crowdsourcing: Conceptualization, literature review, and future agenda", International Journal of HumanComputer Studies, 2017, pp. 26-43.

[40] C. Moro, Z. Štromberga, A. Raikos, and A. Stirling, "The effectiveness of virtual and augmented reality in health sciences and medical anatomy", Anatomical Sciences Education, 2017, pp. 549-559.

[41] D. Urhahne, S. Nick, and S. Schanze, "The effect of threedimensional simulations on the understanding of chemical structures and their properties", Research in science education, 2009, pp. 495-513.

[42] M. Keehner and P. Khooshabeh. Computerized Representations of 3D Structure: How Spatial Comprehension and Patterns of Interactivity Differ among Learners. in AAAI Spring Symposium: Reasoning with Mental and External Diagrams: Computational Modeling and Spatial Assistance. 2005.

[43] V. Santangelo, S. Fagioli, and E. Macaluso, "The costs of monitoring simultaneously two sensory modalities decrease when dividing attention in space", Neuroimage, 2010, pp. 2717-2727.

[44] M.A. Pahuta, E.H. Schemitsch, D. Backstein, S. Papp, and W. Gofton, "Virtual fracture carving improves understanding of a complex fracture: a randomized controlled study", JBJS, 2012, pp. e182.

[45] F. Meijer and E.L. van den Broek, "Representing 3D virtual objects: Interaction between visuo-spatial ability and type of exploration", Vision Research, 2010, pp. 630-635.

[46] A.W. Keedy, J.C. Durack, P. Sandhu, E.M. Chen, P.S. O'Sullivan, and R.S. Breiman, "Comparison of traditional methods with 3D computer models in the instruction of hepatobiliary anatomy", Anatomical sciences education, 2011, pp. 84-91. 